\title{
An Active Energy balancing System for Lithium-Ion Battery Pack
}

\author{
Yu Zeng, Zhiwei He, Mingyu Gao, Hongtian Pan \\ Department of Electronic Information \\ Hangzhou Dianzi University \\ Hangzhou, China \\ mackgao@hdu.edu.cn
}

\begin{abstract}
In this paper, a cell balancing circuit for the Lithium-ion battery pack based on the Flyback topology is proposed. Balancing the lithium-ion battery pack is often employed to improve the energy utilization and lifetime of the battery. The proposed circuit uses the minimized power path to simplify the circuit and optimize the balancing efficiency. This paper shows the details of the balancing circuit structure and working principle, introduce the design of the balancing transformer and its theoretical analysis. Finally, experimental results are presented to verify the theoretical analysis.
\end{abstract}

Keywords-Lithium-ion battery; balancing circuit; Flyback topology; energy transfer

\section{INTRODUCTION}

With the advantages of high energy density, low selfdischarge rate, and high single cell voltage [1], lithium-ion batteries are widely used in various occasions. Battery cells are usually connected in series to achieve higher capacity and voltage. As is well known, series connected lithium-ion cells may experience overcharge or over-discharge, which can damage or shorten the battery life. To avoid this critical situation, an energy balancing system for the series connected lithium-ion battery pack is necessary.

In recent years, the application of balancing circuits in lithium-ion battery pack has been widely studied [2]. Resistance energy ullage based circuit has been widely used for its simple implementation and simple operation, but the energy dissipation and the low efficiency are the main drawbacks of this topology. Switch capacitors based balancing circuit uses big capacitors to store and transfer energy with high efficiency, but the structure of this topology is complicated and can only be used to transfer energy between adjacent cells. Flyback DC/DC converter has the advantage of bi-directional energy transfer, compared with the switch capacitor based balancing circuit. But the complex structure and its big volume caused by the big quantities of transformers are the main disadvantages. In this paper, a modified flyback DC/DC converter with a single multiwindings transformer is proposed to decrease the volume and simplify the control.

\section{BALANCING CIRCUIT}

\section{A. The Structure of the Balancing Circuit}

The balancing circuit of flyback converter with RCD snubber is shown in Figure 1[3].A battery pack is formed using four cells, and all the cells in this pack share a common flyback converter. Transformer consists of 4 secondary windings, which are connected to each cell. The primary winding of is connected to the whole battery pack with a Schottky diode . MOSFET switches(i=1,2...,4), are controlled by PWM signals to decide which cell to be balanced. Besides, to protect the MOSFET from highvoltage spike, caused by leakage inductor, a RCD snubber circuit is used.

The system is controlled by a modern 32-bit MCU(Micro Control Unit) STM32F103C8T6. The MCU scans the voltages of each cell, and calculate the average energy capacity of the pack, and decide which cell to be balanced. If one monomer cell's energy is much higher (20\%) than the average, the MCU gives a PWM signal with fixed duty ration to relevant switch and start the balancing circuit. Initially, when the two are in agreement within a 5\% uncertainty in each measurement, the MCU stops the balancing.

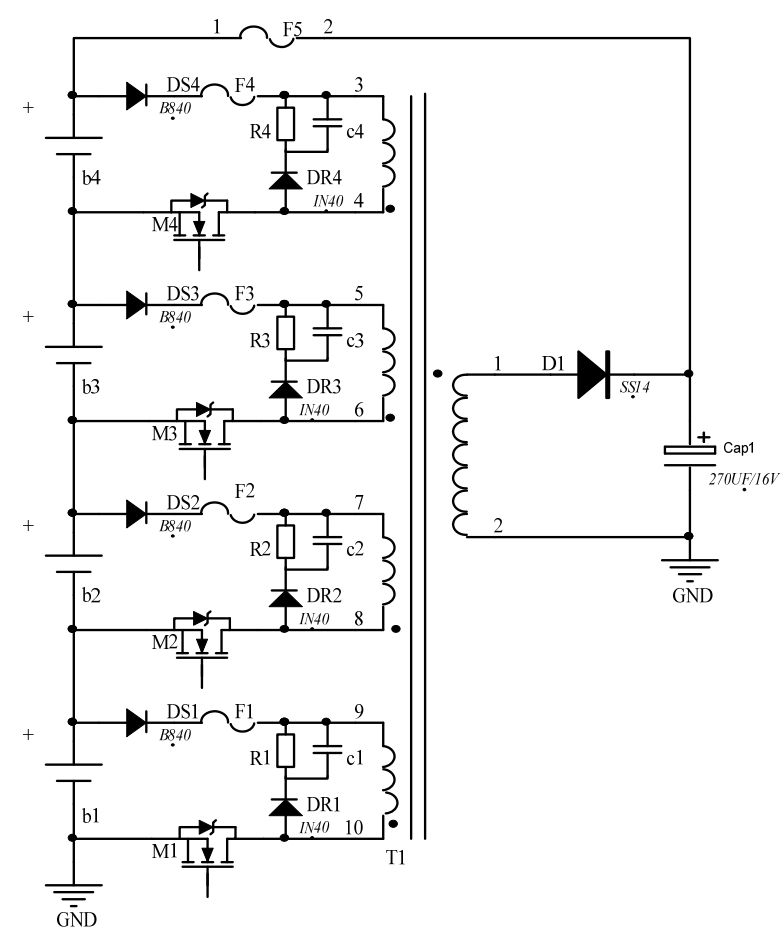

Fig.1 The balancing circuit structure 


\section{B. Operational Mode Analysis}

As showed in Figure 1, if the battery cell 's energy is much higher than the average, the MCU gives out a PWN signal to control the switch, and the principle of the balancing circuit is similar to a flyback switching supply. Take as an example. Assume that has the highest energy, then the MCU controls switch to start the balancing process. Detailed analysis is showed in Figure 2[4].

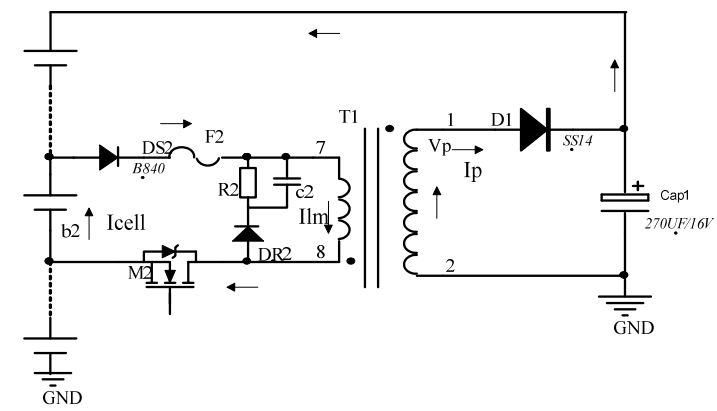

Fig.2 The process of the balancing circuit

$T_{1(1,2)}, T_{1(7,8)}, I_{\text {cell }}, I_{l m}, I_{p}$ represents the primary winding, the secondary winding, the discharge current of cell $b_{2}$, the exciting current in the secondary winding and the exciting current in the primary winding, respectively. When $M_{2}$ is turned on, $b_{2}$ discharges through $D S_{2}$, $T_{1(7,8)}$ and $M_{2}$, while the primary winding is turned off because of the counter electromotive force. So the energy discharged by $b_{2}$ is stored in the transformer $T_{1}$. When $M_{2}$ is turned off, the primary winding conducts, and $T_{1}$ charges the whole battery pack. After such a cycle, top balance is achieved [5], that is, energy is transferred from the cell with the highest energy to the whole battery pack. Diode $D S_{i}(\mathrm{i}=1, \mathrm{i}-1, \mathrm{i}+1 \ldots, 4)$ are used to avoid other secondary winding conducting when cell $B_{i}$ is being balanced[6].

The ideal working waveform is presented in Figure 3. [t0 $\mathrm{t} 3]$ is a whole cycle for the balancing.

Stage 1[t0 t1]: $M_{2}$ is turned on, the lithium-ion battery cell $b_{2}$ discharges and the energy is stored in the transformer. The exciting current $I_{l m}$ can be calculated by voltage-second balance[7].

$$
I_{L m}(t)=\frac{V_{c e l l}}{L m}\left(t-t_{0}\right) .
$$

Where, $L_{m}$ is the inductor of the secondary winding.

Stage 2[t2 t1]: $M_{2}$ is turned off, $D_{1}$ conducts and $I_{p}$ can be gotten by the following formulas.

$$
\frac{V_{P}\left(t-t_{1}\right)}{n^{2} * L_{m}}=\frac{1}{n} * \Delta I_{p} \text {. }
$$

$$
\begin{aligned}
& I_{p}(t)=\frac{1}{n} * \Delta I_{p}-\frac{V_{P}\left(t-t_{1}\right)}{n^{2} * L_{m}} \\
& \Delta I_{p}=\frac{I_{p k}}{n}
\end{aligned}
$$

Stage 3[t3 t2]: $t 3 \sim t 2$ is a dead time, to make sure that the core can be reset completely.

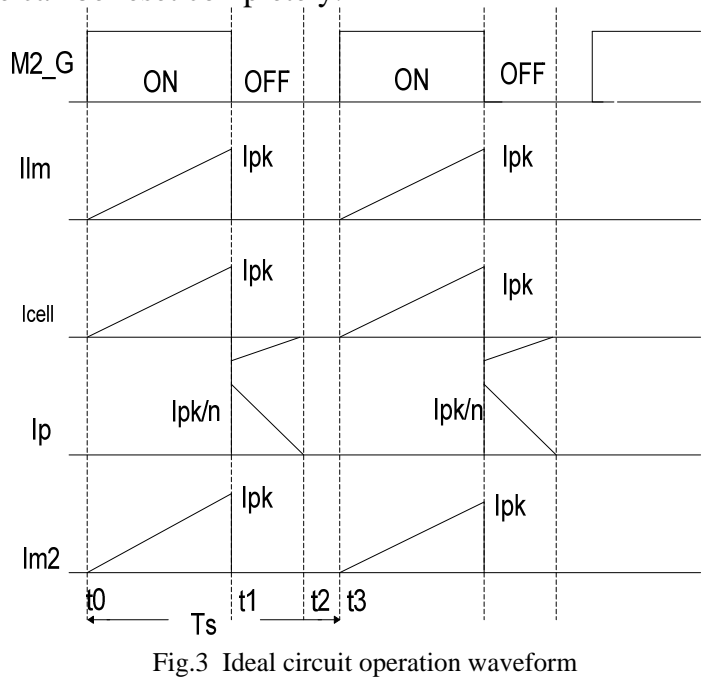

\section{DESIGN OF THE TRANSFORMER}

The most important part of the topology presented is the design of the transformer, which is discussed in detail in this part. The coupling between each winding is of great importance, because poor coupling will decrease the efficiency noticeably. We use "the sandwich winding" to enhance coupling between windings as shown in Figure 4[8].

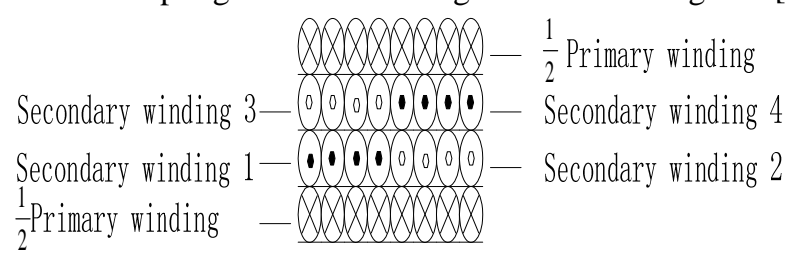

Fig.4 Transformer winding method

The voltage of the battery pack is $13 \mathrm{~V}(3.3 \mathrm{~V}$ for each cell), the frequency of the PWM signal is $22.2 \mathrm{KHz}$ with a duty cycle of $60 \%$, and is $16 \mathrm{uH}$ while is $80 \mathrm{uH}$. The parameters of the transformer are calculated as follows[9].

$\frac{d I_{c e l l}}{d t}=\frac{V_{c e l l}}{L \mathrm{~m}}=\frac{3.3 \mathrm{~V}}{16 u \mathrm{H}}=0.206\left[\frac{\mathrm{A}}{\mathrm{us}}\right]$.

$I_{P K}=\frac{t_{1} * d I_{c e l l}}{d t}=\frac{0.206 * 0.6 * 10^{6}}{22.2 * 10^{3}}=5.562 \mathrm{~A}$.

$W=U * \frac{I_{P K}}{2} * t_{1}=3.3 * \frac{5.562}{2}$

$* \frac{1}{22.2 * 10^{3}} * 0.6 * 10^{6}=248[u j]$. 


$$
\begin{aligned}
& \frac{d I_{l m}}{d t_{2}}=\frac{V_{p}}{L_{P}}=\frac{13 V}{80 u H}=0.1625\left[\frac{A}{u s}\right] . \\
& W=V_{p} * \frac{d I_{l m}}{d t_{2}} * \frac{1}{2} * t_{2} * t_{2} . \\
& t_{2}=\sqrt{\frac{W}{\frac{d I_{l m}}{d t_{2}}}}=\sqrt{\frac{248}{13 * \frac{0.1625}{2}}}=15.3 u S .
\end{aligned}
$$

\section{EXPERIMENT RESULTS}

To verify the operational principles of the proposed cell balancing circuit, an industrial sample is implemented and its parameters are shown in Table 1[10].

\begin{tabular}{|c|c|c|c|}
\hline \multicolumn{3}{|c|}{ Parameters } & Value \\
\hline \multirow{6}{*}{$\begin{array}{l}\text { Cell } \\
\text { balancin } \\
\text { g circuit }\end{array}$} & \multicolumn{2}{|c|}{ MOSFET switch } & AOD436 \\
\hline & \multicolumn{2}{|c|}{ MOSFET driver } & L6384ED \\
\hline & \multicolumn{2}{|c|}{ Schottky diode } & B860 \\
\hline & \multirow{3}{*}{ Transformer } & Core & PQ38 \\
\hline & & $N_{p}: N_{s}$ & 15: 7 \\
\hline & & $L_{p}, L_{m}$ & 80uH ,16uH \\
\hline Battery & \multicolumn{2}{|c|}{ Capacity } & 15.5Ah \\
\hline
\end{tabular}

TABLE I. PARAMETERS FOR THE PROPOSED CELL BALANCING CIRCUIT

Figure 5 shows the experimental waveforms of the industrial sample, in which battery cell has the highest energy. Compared with the ideal waveform, we can draw a conclusion that the presented balancing circuit works well to balance the energy between cells.

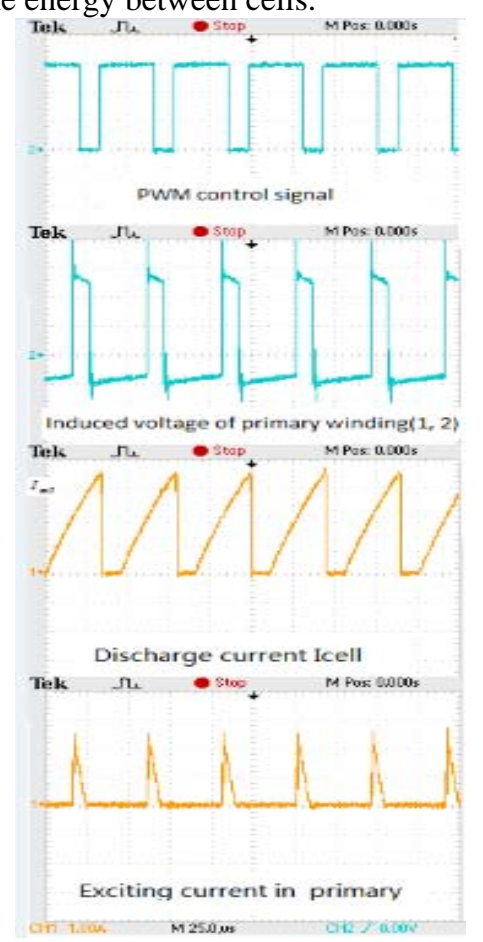

Fig.5 Actual circuit operation waveform
In order to perceive the effect of the balancing circuit directly, two experiments are conducted. Firstly, the battery pack is discharged without balancing; the result is shown in Figure 6. Then we discharge the battery pack with the presented balancing circuit, and the result is shown in Figure 7.

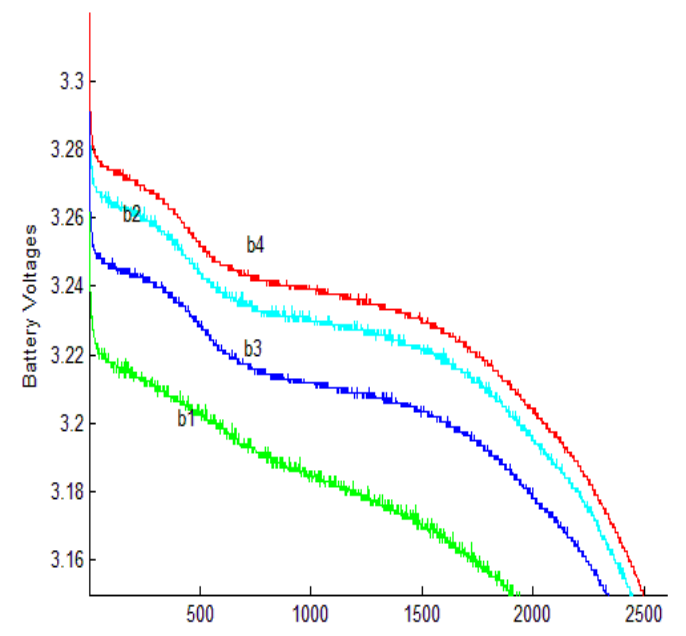

Fig.6 Battery pack discharge without of balance circuit

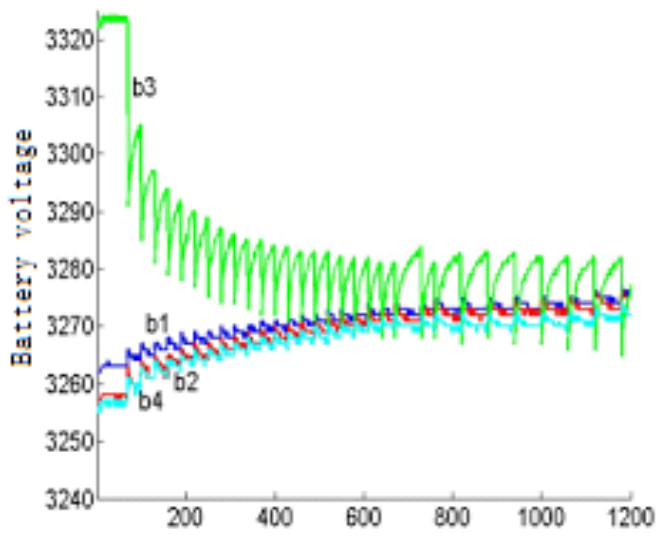

Fig.7 Balance result of battery pack

From the above experimental results, We can see that the proposed cell balancing circuit can balance the energy between cells efficiently and therefore extend lifetime of the battery pack.

\section{CONCLUSIONS}

In this paper, a modified flyback converter balancing circuit is carried out. It has the advantages of lower power dissipation and easy operation compared with conventional passive balancing procedure and switch capacitor balancing circuit. The main disadvantage is that in the low voltage and high current situation, diodes consume too much power. In 
order to improve the efficiency, synchronous rectification will be used in the next version.

\section{ACKNOWLEDGMENT}

This work is supported by the Nature Science Foundation of China (NSFC) Grant \#60871088, and \#61172132, Zhejiang Provincial Natural Science Foundation of China Grant \#Z1110741, Science \& Technique Innovation Team Project of Zhejiang Province Grant \#2012R1008-08, \#2012R1008-09, Zhejiang Educational Committee Foundation of China Grant \#Z201122745.

\section{REFERENCES}

[1] Yuping Wu, Xiaobing Dia, Junqi Ma. Lithium ion Battery application and practice. Beijing: Chemical Industry Press,2004

[2] Hong-Sun Park, Chong-Eun Kim, and Gun-Woo Moon, Charge Equalization with Series Coupling of Multiple Primary Windings for Hybrid Electric Vehicle Li-Ion Battery System [J]. IEEE 2007, 14244-0655-2.

[3] Sanjaya Maniktala, Zhiqiang. Switching Power Supplies A to Z[M]. Beijing: Press of People's Posts and Telecommunication. 2010
[4] Carl Bonfiglio, Member, A Cost Optimized Battery Management System with Active Cell Balancing for Lithium Ion Battery Stacks [J]. IEEE 2009 978-1-4244-2601-0.

[5] Robert W.Erickson, Dragan Maksimovic. Fundamentals of Power Electronics[M]. New York: Kluwer Academic Publishers.

[6] Paul Horowitz, Winfield Hill, The Art of Electronics, Second Edition[M]. Beijing: Publishing House of Electronic Industry.

[7] Thanh Hai PHUNG, Jean-Christophe CREBIER, Alexandre CHUREAU, Optimized Structure for Next-to-Next Balancing of Series-Connected Lithium-ion Cells[J]. IEEE 2011, 978-1-42448085-2.

[8] Hong-Sun Park, Chong-Eun Kim, and Gun-Woo Moon, Two-Stage Cell Balancing Scheme for Hybrid Electric Vehicle Lithium-Ion Battery Strings[J]. IEEE 2007, 1-4244-0655-2.

[9] Jong-Won Shin, Gab-Su Seo, Chang-Yoon Chun, Selective Flyback Balancing Circuit with Improved Balancing Speed for Series Connected Lithium-ion Batteries[J]. IEEE 2010,978-1-4244-5393-1

[10] George Altemose , Peter Hellermann , Active Cell Balancing System using an Isolated ShareBus for Li-Ion Battery Management[J]. IEEE 2011, 978-1-4244-9877-2. 